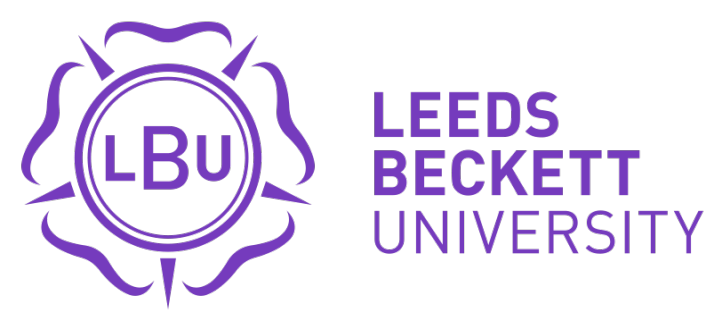

Citation:

Curcuruto, MM and Mearns, KJ and Mariani, MG (2016) Proactive role-orientation toward workplace safety: Psychological dimensions, nomological network and external validity. Safety Science, 87. 144 - 155. ISSN 0925-7535 DOI: https://doi.org/10.1016/j.ssci.2016.03.007

Link to Leeds Beckett Repository record:

https://eprints.leedsbeckett.ac.uk/id/eprint/2477/

Document Version:

Article (Accepted Version)

The aim of the Leeds Beckett Repository is to provide open access to our research, as required by funder policies and permitted by publishers and copyright law.

The Leeds Beckett repository holds a wide range of publications, each of which has been checked for copyright and the relevant embargo period has been applied by the Research Services team.

We operate on a standard take-down policy. If you are the author or publisher of an output and you would like it removed from the repository, please contact us and we will investigate on a case-by-case basis.

Each thesis in the repository has been cleared where necessary by the author for third party copyright. If you would like a thesis to be removed from the repository or believe there is an issue with copyright, please contact us on openaccess@leedsbeckett.ac.uk and we will investigate on a case-by-case basis. 
Proactive Role-Orientation Toward Workplace Safety: Psychological Dimensions, Nomological Network and External Validity

\author{
Matteo Curcuruto \\ Leeds Beckett University
}

Kathryn J. Mearns

University of Bergen

\author{
Marco M. Mariani \\ University of Bologna
}

(manuscript accepted for publication in Safety Science)

Author note: Matteo Curcuruto, School of Social Sciences, Leeds Beckett University, Leeds, United Kingdom; Kathryn J. Mearns, School of Psychology, University of Bergen, Bergen, Norway;

Marco G. Mariani, Department of Psychology, University of Bologna, Bologna, Italy. The correspondence concerning this article should be addressed to: Matteo Curcuruto, School of Social Sciences, Leeds Beckett University, Calverley Building, Portland Way, Leeds LS1 3HE. Email: M.MA.Curcuruto@leedsbeckett.ac.uk 


\section{Proactive Role-Orientation toward Safety Management: Psychological Dimensions, Nomological Network and External Validity}

\section{Introduction}

Many authors have stressed the importance of considering the proactive contribution by individuals and teams in achieving the desired level of safety across different organizational settings (Hollnagel, Paries, Woods, \& Wreathall, 2012; Reason, 2008). Understanding what motivates employee proactivity toward risk management is an important part of changing unsafe conditions and increasing organizational capability to prevent accidents (Mariani, Solda, \& Curcuruto, 2015; Scott, Fleming, \& Kelloway, 2014). Within this framework, the conceptualization of proactive role orientation toward safety management has emerged as a broad set of psychological and motivational orientations by individuals and teams in preventing accidents, managing safety-related issues in the day-by-day individual and teamwork activities and improving workplace safety conditions (Curcuruto \& Griffin, in press; Hofmann, Morgerson, \& Gerras, 2003; Turner, Chmiel, \& Wall, 2005; Weick \& Sutcliffe, 2007). The importance of the construct and its related phenomena have been highlighted by both researchers and practitioners, considering different perspectives of analysis in organizational and industrial settings: the impossibility to predict all the risk factors and threats for health and safety (Peirò, 2008; Vogus, Sutcliffe, \& Weick, 2010); organizational learning and improvement (Curcuruto, Guglielmi, \& Mariani, 2014); development of human resources capability (Griffin, Hodkiewicz, Dunster, Kanse, Parkes, Finnerty, Cordery, \& Unsworth, 2014); sustainability of the work experience over time (Clarke, 2010; Hofmann \& Tetrick, 2003).

In line with this, a great deal of research in applied psychology has shown the importance of workers' motivation to participate in the spread of safety in work organizations (i.e. Christian, 
Bradley, Wallace, \& Burke, 2009). Nevertheless, as recently reported by Zohar (2008), relatively little research has been focused on the explanation of the different psychosocial mechanisms which lead to proactive safety behaviors, like safety initiative and changing-oriented safety citizenship (Curcuruto, Guglielmi, \& Mariani, 2013). Moreover, whereas the general research tendency is mainly oriented towards the "preventive-focused" perspective of analysis of human contributions to workplace safety (i.e. reducing errors and risk; avoidance of negative events; compliance with safety procedures) (Higgins, 2012; Hollnagel et al., 2012; Reason, 2008; Wallace \& Chen, 2006), little research has been focused to explore more "promotion-focused" perspectives of safety (Kark, Katz-Navon, \& Delegah, 2015). This also resonates with Hollnagel's (2014) concepts of Safety I and Safety II in relation to safety management. Safety I refers to the traditional form of safety management, where the objective is to ensure that accidents and incidents are kept to a minimum or even prevented altogether. In this perspective, safety is defined as a state where as few things as possible go wrong, due to technical, human and organizational causes. This leads to a reactive approach where management responds to what has gone wrong or what could go wrong (i.e. correcting malfunctions, failures, potential risks). On the other hand, Safety II involves focusing on what goes right, which is a proactive approach to safety management based on a different set of managerial principles, such as, the continuous anticipation of possible developments and events in the future, and the consequent capability for the organizations to operate constant adjustments of their performances, assuring successful variability, adaptivity and flexibility of their socio-technical systems. In relation to the current paper, Safety II measures efficacious actions and everyday acceptable performance, which can stem from the proactive orientation of the workforce toward the continuous improvement of safety in the daily organizational activities.

In agreement with these reflections, the principal purpose of the present article is to define and validate a measurement tool aimed to assess the motivational components of a proactive 
orientation by individuals toward the active prevention of accidents and injuries in the workplace, which may express a more positive and "promotion-focused" approach in safety management.

The paper aims to offer relevant contributions to the existing organizational behavior literature in different ways. Firstly, we aim to test a specific measurement model to assess the different motivational facets of the construct of proactive role orientation toward safety management in the workplace. In doing this, the general organizational paradigm of proactive motivation (Parker, Bindl, \& Strauss, 2010) and dynamic capabilities (Griffin, Cordery, \& Soo, 2015) are considered here as a theoretical basis to draw on and describe multiple motivational drivers of a proactive orientation toward safety management, accident prevention and improvement of safety systems. To the best of our knowledge, even if the paradigm of proactivity has been investigated in different organizational research fields (i.e. socialization; innovation), until now no study has been focused on how multiple proactive motivational states support the emergence of proactive phenomena in the domain of workplace safety. Secondly, our test would allow us to define a diagnostic model which is potentially valid across different organizational settings and formal role definitions, considering the generalizability of the construct of proactive motivation (Parker et al., 2010). Thirdly, we aim to show how our assessment tool is related to relevant behavioral criteria of safety proactivity, like safety initiative (Kark et al., 2015; Zohar, 2008), safety voice (Tucker \& Turner, 2015; Conchie, 2013), and prosocial safety citizenship (Curcuruto et al., 2013; Griffin \& Curcuruto, 2016).

The paper is structured as follows. First, we will briefly discuss the assumptions underlying and the dimensions comprising the new proposed assessment model of proactive safety orientation. Then, empirical findings are presented in relation to two complementary steps of validation of a new psychometric tool: a) the investigation of the internal factor structure and dimensionality of the measurement model b) a further step of construct validation involving the definition of a nomological network of the constructs underlying our new psychometric tool. Construct validity 
evidence based on nomological validity refers to the degree to which a new construct behaves as it should expected to do within a system of related constructs (the nomological network) on the basis of the conceptual assumptions deducted by the theoretical framework of reference. In the present study, we will provide evidences of nomological validity exploring the correlations of our assessment model with other existing well-established safety-specific organizational dimensions (i.e. transformational leadership) and expected behavioral criteria outcomes (i.e. proactive safety behaviors), using both self-reported and external measures.

\section{Theoretical foundations: paradigms of safety proactivity in organizations}

Research on socio-technical systems has broadly discussed the concept of proactive orientation toward safety management as the expression of the whole organizational system to enhance the ability at all levels to create safe processes, to monitor and revise organizational safety models, and to use resources proactively in the face of disruptions or ongoing production and productivity pressures (Curcuruto \& Griffin, in press; Hollnagel et al., 2012; Reason, 2008; Weick \& Sutcliffe, 2007; Zohar, 2008). For instance, the 3Cs resilience model by Reason (2008) has embedded the concept of safety proactivity considering managerial orientations of commitment, cognizance and capability by the organizations. Similar considerations have been advanced in relation to other socio-technical paradigms, considering organizational constructs like collective mindfulness and engineering resilience (Hollnagel et al., 2012; Weick \& Sutcliffe, 2007).

At the individual level of analysis, two studies of significance (Hofmann et al., 2003; Turner et al., 2005), considered how people define organizational citizenship behaviors (OCB) as a part of their own expected safety role in the organization, elaborating the construct of safety citizenship role definition. This concept is related to the idea that people develop specific perceptions about safety-related behavioral role expectations during interactions with other day-by-day organizational actors, and go beyond their formal task description. Nevertheless, recent reviews of research on inrole definition pointed out some limits of this approach. Firstly, the implicit lack of consideration of 
individual motivations and self-perception in the role-expansion processes. In most cases workers would be considered as passive actors who react to external stimuli and expectations, without any consideration for the active role played by their motivations and self-perceptions in the construction and extension of their perceived role toward specific organizational domains (i.e. Grant \& Hofmann, 2011). Second, the conceptualization and measures of the specific construct of safety citizenship role-definition appears to be mono-dimensional, being focused only on the perceptions of others' expectations on the enacting of several extra-role behaviors with implications for workplace safety, without any consideration of the influence of workers' cognition, affect and perception.

In contrast with the paradigms of safety citizenship in the definition of safety-specific role orientations we propose an alternative approach, which differs on two points. Firstly, it aims to embrace a positive perspective of the individual, who is assumed to be an active element of the organizational system whose continuous adaptation and initiative efforts over time enable the whole system to self-improvement, resilience and development, beyond simply bringing it back from the brink of accidents and negative events (Hollnagel et al., 2012; Reason, 2008). Secondly, it aims to consider multiple psychological mechanisms, which drive human operators to achieve the highest levels of proactivity toward safety management, rather than the individual's perception of social expectations or desired behavioral models in their organizations (Parker et al., 2010).

\section{Proactive motivation, future orientation and safety management in the workplace}

A novel way to consider the concept of proactivity in the domain of safety and plug the existing gap in the literature has been recently proposed by Curcuruto and Griffin (in press), on the basis of existent models and concepts such as proactive motivation (Parker et al., 2010) and future orientation (Griffin et al., 2015) in the broader literature of organizational psychology.

On one hand, the proactive motivation paradigm is focused on the degree to which employees develop a proactive orientation toward a specific domain of organizational life on the 
basis of multiple motivational states. Although there are many organizational targets and future improvement states that an individual might envisage, Parker et al. (2010) identified two broad categories of stable motivational states which support proactive role orientations and behaviors within a particular organizational domain: a) "can do" motivations which refer to motivational states of perceived self-capability, like self-efficacy and perceived control; b) "reason to" motivations in terms of subjective-values states toward specific organizational targets, like the constructs of psychological ownership and felt responsibility.

Proactive management of organizational safety is also related to specific future orientations by individuals, teams and organizations (Curcuruto \& Griffin, in press; Griffin et al., 2015; Hollnagel et al., 2012): anticipation of critical events; continuous improvement of safety standards; active learning from errors. For individuals, a future orientation enables individuals to adopt more proactive strategies for goal achievement (Strauss, Griffin, \& Parker, 2012). At the organizational level, attention to future change has been shown to increase the capacity of organizations to proactively implement adaptive routines (Griffin et al., 2014; in press). Overall, these long-term orientations probably support in a distinctive way safety-specific proactivity phenomena in organizational life (Frese \& Fay, 2001; Greenglass, 2002; Parker \& Wu, 2013).

In the light of these main conceptual foundations, we aim in the following sections to review the principal typologies of proactive motivations and future oriented constructs identified by Curcuruto and Griffin (in press), describing their specific relevance for safety. Table 1 provides a set of definitions and key references regarding the constructs that are described more in detail in the next sections.

Insert Table 1 about here 


\subsection{Can do motivation and safety management}

Role breadth self-efficacy. Generally, the self-efficacy concept refers to people's judgments about their capability to perform particular domain tasks and organize and execute courses of action required to attain designated performances. Research has shown that employees who feel capable of performing particular tasks will perform them better (Bandura, 2001), will persist at them in the face of adversity (Speier \& Frese, 1997), and will cope more effectively with change (Fuller, Marler, \& Hester, 2012). The related concept of role breadth self-efficacy (RBSE) refers to employees' perceived capability to carry out a broader and more proactive interpersonal and integrative set of work tasks and goals beyond prescribed requirements, as a psychological "can do" mechanism (Parker et al., 2010). RBSE has been shown to be associated with outcomes such as proactive work performance (Griffin, Neal, \& Parker, 2007), taking-charge behaviors that challenge the organizational status quo and suggesting organizational improvements (McAllister, Kamdar, Morrison, \& Turban, 2007).

Despite the potential influence of the construct on safety participation by workers (Geller, 2002), little attention has been directed toward the concept in a safety context (Katz-Navon, Naveh, $\&$ Stern, 2007). With this rationale, this construct might be considered in relation to the extent to which people feel confident that they are able to carry out a broader and more participative role in the maintenance and improvement of safety aspects, beyond formalized tasks and prescribed technical requirements. For example, analyzing potential problems and risks to propose a solution, or discussing with superiors ways to reduce dangers, or making suggestions for improvement.

Perceived control. Generally, concepts like perceptions of influence and control in work settings have been studied as the conviction of having a significant impact over the relevant operational processes and final outcomes of work, and they have been considered as dimensions of psychological empowerment (Spreitzer, 1996) associated with a greater efficacy and participation in teams (Mathieu, Gelson, \& Ruddy, 2006), personal initiative (Frese \& Fay al., 2001), favorable 
work-outcomes and generally better psychological person-environment fit (Parker et al., 2010). For these reasons these constructs have been categorized as 'can do' motivation mechanisms of proactivity (Parker et al., 2010).

Concurrently with this we propose the concept of perceived control over safety issues as the degree to which people perceive themselves as affecting the safety process and organizational actions related to safety maintenance and improvements in organizational units and teamwork. Unlike other connected constructs like safety locus of control (Christian et al., 2009), which were considered as personal beliefs related to safety outcomes (i.e. injuries and accidents), the concept of perceived safety control is here conceptualized as more related to day-by-day work activities and more distal from the outcome of injuries and accidents.

\section{2 Reason to motivation and safety management}

Psychological ownership. Generally, the psychological ownership construct has been described as an affective motivational construct defined as the state in which individuals feel as though the target of ownership is theirs and reflects the individual's awareness, thoughts, and beliefs regarding the target of ownership (Pierce, Jussila, \& Cumming, 2009). This psychological state was described as the cause of a broader role orientation toward specific organizational instances (i.e. production; quality) (Crant, 2000). Individuals with flexible role orientations define their roles broadly and, as such, feel ownership of activities and problems beyond their immediate set of technical role tasks, seeing them as "my job" rather than as "not my job" (Parker, William, \& Turner, 2006).

In line with this, we propose the construct of safety ownership as the extent to which people feel that organizational safety is something they "own". Workers who experiment with high levels of subjective psychological ownership for safety consider safety issues, processes and problems as something of personal interest and concern, beyond the formal boundaries defined by their job descriptions. Consequently, if they see something that is not done well, they will show initiative in 
order to rectify it. Unlike the construct of safety citizenship definition (Hofmann et al., 2003; Turner et al., 2005), psychological ownership for safety is theoretically driven by psychological internalization (Gagnè \& Deci, 2005). High levels of safety ownership would be indicated by individuals who also feel concern for high quality safety processes in work-teams and organizational units, for co-workers' involvement in safety, for continuous improvement of safety management processes and for helping to implement safety programs as part of a team or organization. By contrast, an employee who sees their safety role exclusively in terms of the correct use of protective equipment and compliance with norms and procedures has a narrow psychological ownership for safety.

Felt responsibility. Constructs like personal responsibility were proposed by several scholars (Fuller et al., 2012; Morrison \& Phelps, 1999) as important antecedents of personal initiative and taking charge behaviors, in terms of "reason to" motivational mechanisms (Parker et al., 2010). In the safety culture research, the concept of responsibility for safety has been discussed in the high reliability systems (Weick \& Sutcliffe, 2007) and behavioral safety paradigms (Geller, 2002). In such systems, the whole workforce becomes involved in how safety is managed in their organization, and where everyone feels responsible for the safety of others. The development of feelings of personal responsibility over formal role accountability for safety has been indicated as fundamental to achieve advanced safety culture systems (Geller, 2002; Vogus et al., 2010), where everyone feels responsible for setting and striving to reach safety goals in work-teams and department units, regardless of their rank (Guldenmund, 2010; Reason, 2008).

Thus, we propose psychological dimensions of personal felt responsibility for safety as a measure of the extent to which people are willing to taking charge for contributing to setting and striving to meet organizational safety goals beyond their formal role accountability. Whereas the previous concept of safety ownership is focused more on the work and organizational processes which support and innovate safety (team-coordination activities, appropriate training, developing 
new procedures, participative programs), the felt responsibility construct would be focused more on one's own role in striving to achieve organizational safety goals, like reducing accidents, and avoiding critical hazards or achieving safety improvement targets.

\subsection{Future orientation and safety management}

Anticipation orientation. In general safety research, concepts such as anticipation and prevention orientations was broadly embedded in paradigms such as mindfulness and chronic unease, which lead to proactive and pre-emptive analyses and discussion of risks and threats (Griffin et al., 2014; Weick \& Sutcliffe, 2007). Similarly, the resilience paradigm (Hollnagel et al., 2012) was centered on how safety management implements ways to enhance the organizational ability to create processes that anticipate, monitor and revise risk in the face of disruptions or ongoing production pressures. At a more individual level of analysis, the concept of anticipation has been discussed in the field of occupational health psychology, considering future oriented coping strategies by individuals to face risks and potential threats to their personal health and safety (Greenglass, 2002; Peirò, 2008).

According to these contributions, we define the dimension of safety prevention orientation as a future oriented mind-set by individuals to anticipate potential and uncertain hazards and critical situations for safety. From a practical safety perspective, we predict that people who assume an anticipatory mindset will be more inclined to mentally anticipate the changing shape of risk before it appears and consequent damage occurs.

Improvement orientation. In general organizational research, constructs like learning and change orientations have been theorized as relevant drivers of organizational improvement and development (Frese \& Fay, 2001; Parker et al., 2010). Similarly, in safety research, the concept of continuous improvement of systems and procedures has been discussed in relation to the notions of "learning culture" (Reason, 2008) and "commitment to resilience" (Weick \& Sutcliffe, 2007). 
In line with recent promotion-based approaches to safety management (Kark et al., 2015), we may consider the concept of safety improvement orientation by individuals as the propensity to strive to exceed safety standards, for example, being receptive to accepting new ways to do things more safely, to acquire new knowledge, abilities or competences to increase safety in work activities. Workers trying to improve safety in the workplace (i.e. procedures, practices or instruments) are willing to question the ways things are done, and are willing to think about ways to improve, even if work activities are running smoothly and there is no evidence of apparent threat.

\section{Research hypotheses on factor structure and nomological network}

In the light of the motivational paradigm of proactivity (Parker et al., 2010), we postulate that the six psychological dimensions described above are motivational drivers of a proactive orientation by individuals toward the active management of occupational safety instances in the workplace: role-breadth self-efficacy; perceived control; psychological ownership; felt responsibility; anticipation orientation; improvement orientation.

Also, we present a research hypothesis on the existence of a higher second-order factor structure of the construct of proactive safety-role orientation by employees toward the management of safety in the workplace. Such a hypothesis would appear to be coherent with both conceptual and methodological research instances. From a theoretical perspective, the concept of proactivity toward safety management has been discussed as broad multi-dimensional construct (Zohar, 2008), and expressed by a set of different managerial orientations (Reason, 2008). In a more methodological perspective (Judge \& Kammeyer-Mueller, 2012), the hypothesis of a higher hierarchical and superordinate structure might be pertinent for a complete understanding of the construct and to "explain how the construct and its dimensions relate to one another" (Edwards, 2001; p. 149).

Hypothesis 1: A proactive safety-role orientation in the workplace is a higher-order category of motivation that is identified by six first order factors: role-breadth self- 
efficacy, perceived control, psychological ownership, felt responsibility, anticipation orientation, and improvement orientation.

This appears conceptually justified since different criteria and outcomes have been hypothesized by the current scientific literature as an expression of safety proactivity by individuals, a general measure of proactive safety-role orientation in the workplace might be considered a useful contribution in terms of criterion-related validity and abstraction to match a more appropriate level of prediction and generalizability across different targets and safety proactivity criteria (Edwards, 2001; Judge et al., 2012), like safety initiative (Simard \& Marchard, 1995) and safety voice (Tucker \& Turner, 2015).

Hypothesis 2: The general measure of the higher superordinate factor category of proactive safety-role orientation is positively associated to proactive behavior related to safety management in the workplace like safety initiative $(2 a)$ and safety voice behaviors $(2 b)$.

Moreover, as past studies showed that proactivity phenomena are likely to change a workplace and create outcomes that can observed in order to provide evidence for external validity of the proactive safety motivation construct (Griffin et al., 2007; Parker et al., 2006), we expected to find positive correlation links of the general measure of the construct of proactive role orientation toward safety management with external measures of safety related issues like supervisors' behavioral ratings and objective measures of safety in organizations (i.e. spontaneous suggestions and/or initiatives by employees for the improvement of safety related issues). Finally, we expected to find negative correlations of the PRO-SAFE measure with negative events for work safety that are actually recorded in the organizations with objective methods (i.e. injuries, risky events). 
Hypothesis 3: The general measure of the higher order category of proactive safety-role orientation is positively associated with supervisors' behavioral ratings of spontaneous suggestions and/or initiatives by employees for the improvement of safety related issue (3a), and negatively associated with critical events for safety (i.e. injuries, risky events) $(3 b)$.

As far as the potential antecedents are concerned, positive correlations of the PRO-SAFE scale are expected with the construct of safety-specific transformational leadership, which is theorized as the exercise of a leadership style (i.e. intellectual stimulation; inspirational motivation; idealized influence; individualized consideration), which positively affects individual agency in the workplace. As previous research has verified empirical associations of this kind of leadership with proactive forms of safety participation by employees like safety initiative (Clark, 2010) and safety voice (Conchie, 2013), we hypothesized that:

Hypothesis 4: The general measure of the higher order category of proactive safety-role orientation in the workplace is positively associated with the construct of safety-specific transformational leadership.

\section{The empirical research}

In the sections that follow, we present two empirical studies to assess the validity of a multidimensional questionnaire, which we named the Proactive-Safety Role Orientation questionnaire (acronym: PRO-SAFE). First, we subject the new questionnaire to confirmatory factor analysis (CFA) to assess its factor structure and we provide evidence of the measure's 
stability in two different industrial samples. Then, we will evaluate different aspects of construct validity of the new tool (nomological network; external validity). More details are reported below.

\subsection{The dimensionality of the PRO-SAFE questionnaire}

The first part of our study aimed to deepen the dimensionality of the conceptual model of the measurement tool and the relationship between the constructs. Confirmatory factor analyses were performed on three samples from different organizations.

Based on the theoretical framework presented above, the PRO-SAFE questionnaire ${ }^{1}$ was developed as a measurement tool to assess the multiple psychological drivers of a proactive orientation toward safety management in the workplace. Both deductive and inductive processes were used for item generation through the following steps (Hinkin, 1998): (1) identification phase of existing psychometric instruments in the proactivity literature to adapt to safety research contents by a research team composed of faculty members and research associates, (2) content item interviews phase with safety experts (a sample of 20 team safety heads and managers), (3) a study on the psychometric reliability for the final reduction and selection item, with a short survey conducted on a small sample of technical workers and a final interview phase (Stanton, Sinar, Balzer \& Smith, 2002). A more detailed description of this item identification and adaptation process is reported in the appendix A.

Amongst others, the most relevant existing scales which were adapted are: flexible roleorientation (Parker et al., 2006), felt responsibility to change (Morrison et al., 1999), role breadth self-efficacy (Parker, 1998), anticipatory coping scales (Greenglass, 2002), psychological empowerment (Spreitzer, 1996), change orientation (Parker et al., 2006). A list with a description of the contents of the questionnaire scales is reported in table 5.

\subsubsection{Sample}

\footnotetext{
${ }^{1}$ The PRO-SAFE questionnaire tool (acronym of: proactive safety-role orientation questionnaire) was originally developed in the unpublished doctoral dissertation of the first author. However, the statistical findings presented in this study contribute to test the factor structure of the tool using multiple organizational samples and work contexts.
} 
We conducted this dimensionality study on two large organization samples. More details on characteristics of samples and organizations are reported below.

Sample 1: Chemical operators. The first sample of our study was composed of approximately 400 employees from a plastic production company in Northern Italy. This type of chemical industrial context was characterized by a high-reliability organization system in terms of a strong emphasis on proactive, anticipatory and self-generative management of safety issues in a socio-technical system (Weick \& Suitcliffe, 2007). A total of 327 valid questionnaires were collected at the beginning of the annual "safety day" meeting. Response rate was $81 \%$. The sample was comprised of men (77\%), principally employed in the production (43.1\%), logistic (17.3\%), technical service $(13.5 \%)$ and research and development sectors $(8.3 \%)$. Average age and job tenure were $43.1(\mathrm{SD}=8.7)$ and $19.8(\mathrm{SD}=9.8)$ years, respectively.

Sample 2: manufacturing operators. The second sample of workers was from a manufacturing plant in Northern Italy, with about 250 workers. 196 questionnaires were returned for a final participation rate of $77 \% .89 \%$ of respondents were men. Respondents were from production departments $(47.6 \%)$, chemical treatment department $(21.1 \%)$, and maintenance and support staff $(15.1 \%)$. Average age in this sample was $35.3(\mathrm{SD}=8.2)$, with an average of job tenure of 7 years $(\mathrm{SD}=5.3)$.

\subsubsection{Survey procedure and administration}

All the samples were contacted thanks to the support of a University foundation. The questionnaires were collected using a procedure ensuring anonymity, acceptance and discretional participation in the survey. All participation was voluntary and there was no reward or penalty for not participating. Survey instruments were used for research purposes only.

The data were collected by a questionnaire consisting of 24 items in relation to six areas presented in the literature section. A brief description of their contents is reported in table 6. For every dimension we used six items evaluated on a five-point Likert scale. Participants were asked to 
express their degree of agreement with every item statement $(1=$ strongly disagree; $5=$ strongly agree).

\subsubsection{Results}

Descriptive, correlation and reliability statistics of the scales of the PRO-SAFE questionnaire are reported in table 2. In the next paragraphs we report information about the goodness of the hypothesized model in the overall sample and in its two subsamples.

Insert Table 2 about here

General model comparisons. We performed a confirmative CFA analysis on the 24-item PRO-SAFE questionnaire to compare different models in order to verify the validity of a model with a higher hierarchical factor structure, with a superordinate dimension of proactive role orientation toward safety management in the workplace. As reported by Avey, Avolio, Crossley and Luthans (2008), we considered a framework for second order multi-dimensional constructs where the second order factor represents the common variance between the first order components. While these concepts have been defended qualitatively, a model comparison of hypothesized versus alternative model offers support to these conceptual arguments.

Table 3 reports a summary of the fit indices of the hypothesized model, compared with a set of alternative models. The hypothesized model yielded a CFI of .95 and a RMSEA of .04. In every case, the average of the item loading on every factor was higher than the correlation among the latent factors, giving us additional evidence of internal discriminative validity among the components of the model (Fornell \& Larcker, 1991). Then a series of statistical comparisons of the hypothesized factor model with three competing model solutions presenting a degree of increasing complexity of the conceptual framework underlying: a) alternative model 1, composed of three distinct general first order factors: can do motivation, reason to motivation, and future orientation; 
b) alternative model 2 defined by the six safety-specific psychological factors described above, but without any second-order factor; c) alternative model 3 composed of six safety-specific psychological factors loading in two superordinate dimensions: proactive motivation (perceived control; role breadth-self efficacy; psychological ownership; felt responsibility) and future orientation (anticipation orientation; improvement orientation). In addition, a first order model defined by a single method-factor was included in our analysis (with all items loading in a single first order factor), in order to control the potential method-bias effects.

Next, BIC index (Bayesian information criterion) was used to compare the models. In statistics, the Bayesian information criterion (BIC) is a criterion for model selection among a finite set of models. Given that - when fitting models - it is possible to increase the likelihood by adding parameters, but doing so may result in overfitting. BIC index try to resolve this problem by introducing a penalty term for the number of parameters in the model. In line with this principle, the model with the lowest BIC must be preferred. Overall, in the current study, BIC index showed that the proposed hierarchical factor model was the best statistical model solution, giving support to our hypothesis 1 .

Insert Table 3 about here

Model fit in the two subsamples. More specific analyses in the three subsamples also showed a general fit of the proposed assessment model in every subsample of workers. Firstly, we verify the goodness of a model with the superordinate factor dimension of second order. In the chemical sample, the model presented good fit indices $(\mathrm{CFI}=.94$; RMSEA $=.05)$. In the manufacturing sample we found fairly acceptable fit indices $(\mathrm{CFI}=.94 ; \mathrm{RMSEA}=.06)$. Tables 4 and 5 showed more detailed information on the model comparison for every subsample. More detailed information of loading factor indices of the items of the questionnaire are reported in table 
6 for each sample. Overall, these findings seem to suggest that the PRO-SAFE questionnaire might be used as a general measurement tool of the overall concept of proactive role orientation toward safety management, showing consistency across two different industrial samples.

Insert Tables 4, 5 and 6 about here

\section{Nomological network: antecedents, behavior criteria, external outcomes}

In the second part of our study, evidence of construct validity of the general PRO-SAFE questionnaire are shown using a correlation approach as in previous validation research (Avey et al., 2008). Both correlation with antecedents, behavior criteria and safety outcomes were investigated.

\subsection{Nomological network measures}

In addition to the PRO-SAFE questionnaire, we included other validated psychometric measures related to relevant dimensions described in the proactivity and safety literature.

Proactive safety behaviors were measured with two different scales to test for criterion validity, using a 5-point response scale range from 1 (strongly disagree) to 5 (strongly agree) (Hofmann et al., 2003). A four-item scale of safety voice behavior was used to measure the degree to which respondents spoke up about safety concerns. An example item is "Make recommendations to colleagues on the safety with regard to work activities". Four items were used to measure the tendency of individuals to enact safety initiative behaviors for the improvement of work situations. An example item is "Make suggestions to improve the safety of an activity". With the present sample, all the two scales showed good internal consistency (safety voice: $\alpha=.78$; safety initiative: $\alpha=.75)$.

From a discriminative validity perspective, we also included two measures related to safety behavior not conceptually relates to safety proactivity literature. First, a risk-taking behavior scale was used as a negative indicator of generalized compliance with safety norms and procedures in 
some situations where it might appear advantageous (Mearns, Rundmo, Flin, Gordon, \& Fleming, 2004). An example item is "Not comply with some rule or procedure to be able to achieve good results at work". The scale used a 5-point response scale ranging from 1 (strongly false) to 5 (strongly true). With the present sample, Cronbach's $\alpha$ was .83. Second, a five item-scale of safety stewardship was used to measure pro-social oriented safety citizenship. An example is: "Trying to protect the members of my team from dangers and risks in the workplace". With the present sample, Cronbach's $\alpha$ was .83.

The safety-specific transformational leadership scale (Barling, Loughlin, \& Kelloway, 2002) was used to measure employee perceptions of transformational leadership styles by supervisors, expressly related to safety issues in the workplace. An example item is "My supervisor talks about his values and beliefs on the importance of leadership”. In the original format, all statements were measured on a scale from 1 "not at all" to 5 "frequently". With the present sample, Cronbach's $\alpha$ was .88 .

External measures. The socio-organizational information box at the end of the questionnaire allowed us to cluster the participants from the two organizations into 32 real work-teams in order to test the links of the new assessment tool with external sources of information such as supervisor evaluations and data-archives. Two types of external measures were obtained. First, we obtained the percentage of work group members who made suggestions for safety improvements through a formal suggestion system. We expected that the percentage of members making suggestions in each group would also correlate positively with the average self-ratings of proactive safety orientation (Griffin et al., 2007). The "improvement rate" was obtained considering the frequency index of improvement suggestions per number of members in each of the 32 teams. We considered the information collected six months after the survey. Examples of suggestions are related to the improvement of safety procedures, adaptation of technologies and work-instruments, physical aspects of the work environment. Second, we were able to use the accident databases (minor 
injuries; property damage; near-miss). We expected to find a negative correlation between the averages of the team's relevant negative events for safety with the average of self-ratings of proactive safety orientation (Neal \& Griffin, 2006). The "critical incident rate" was obtained considering a jointed index with the average of the critical events actually recorded in every workteam in the following semester.

\subsection{Results}

Descriptive and reliability statistics with the relationships between the PRO-SAFE questionnaire and other measures of conceptually potential antecedents and criteria constructs are reported in Table 7.

The general PRO-SAFE measure was positively and strongly related to self-ratings of safety voice $(\mathrm{r}=.54, \mathrm{p}<.01)$ and safety initiative $(\mathrm{r}=.58, \mathrm{p}<.01)$, giving support to our research hypothesis $H 2$ a and $H 2 b$. Moreover, the general measure was weakly related to stewardship behaviors ( $\mathrm{r}=.19$, $\mathrm{p}<.01$ ), which have been considered as a more prosocial form of safety citizenship (Hofmann et al., 2003), and negatively related to risk behaviors $(\mathrm{r}=-.25, \mathrm{p}<.01)$. In addition, and as expected, transformational leadership was positively related to the general PRO-SAFE measure $(r=.42$, $\mathrm{p}<.01$ ), providing support to hypothesis $H 3$.

Insert Table 7 about here

External validity. Interclass correlation indices were computed in order to justify aggregation at the team level of self-reported scores of proactive orientations by workers in order to consider other criteria validation links with external sources of information collected at the team level (Neal \& Griffin, 2006). Results showed an acceptable level (ICC2=.84) above the cutoff of .70 as recommended in the literature (LeBreton \& Senter, 2008). Correlation indices with the external concurrent measures showed acceptable statistical links (critical events: $\mathrm{r}=-.37$; 
suggestion rate: $r=.40$ ), in the light of previous validation research on proactivity phenomena (Griffin et al., 2007; Parker et al., 2006), giving support to our hypotheses $H 4 a$ and $H 4 b$.

\section{General discussion and conclusions}

The empirical findings of the present research offer evidences of validity and consistency about a multi-dimensional measurement tool to assess the different facets of proactive roleorientations by individuals in the management of safety in organizational settings. Our research offer also a conceptual contribution in the light of recent calls by researchers for the investigation of the multiple psychological processes, which sustain a more proactive and promotion-oriented management of safety (Kark et al., 2015; Hollnagel et al., 2012; Reason, 2008; Zohar, 2008).

\subsection{Theoretical implications}

Beyond the methodological instances related to the validation of a new measurement tool, conceptual contributions of the present research might be briefly summarized as: $a$ ) using a motivational perspective to re-elaborate the concept of proactive safety orientation at the individual level of analysis (Reason, 2008) $b$ ) to contribute to the conceptual discussion on a promotionoriented approach to safety research in organizations (Kark et al., 2015) c) to offer empirical support about the validity of the proactive motivation paradigm in safety research domain (Parker et al., 2010).

These points are briefly reviewed below.

a) Firstly, going beyond the existing paradigms of safety citizenship, a conceptual approach based on an integrated approach to multiple psychological states by individuals toward safety management may stimulate further research on the propensity of individuals to develop a broader and participative orientation toward safety promotion in the workplace. For example some of the dimensions described here may be particular salient in specific work situations and interact with work contingency factors, related both to individuals and the organizational context, producing differentiated effects in terms of safety initiative behaviors and courses of actions for the 
improvement and maintenance of safety (Curcuruto, Conchie, Mariani, \& Violante, 2015; Reason, 2008; Zohar, 2008).

b) Secondly, in light of the motivational paradigm of self-regulatory focus and in contrast to previous research, which has mainly focused on a preventive-focus approach to safety (Higgins, 2012; Hollnagel et al., 2012; Wallace et al., 2006), we propose applying the proactive motivation and future orientation paradigms in the safety domain (Study 1) as a promotion-based approach to safety initiative and participation by individuals (Kark et al., 2015). This conceptual assumption appeared to be initially supported by the research findings. In study 2 , we verified strong correlations of the PRO-SAFE general measure with active challenging forms of proactive safety behaviors (i.e. voice; initiative) and external measures related to the effective improvement of the general situation of safety in the workplace (i.e. suggestions for improvement by workers actually recorded in the database). Instead, we verified moderately low correlations with safety citizenship behavior explicitly associated with risk-prevention and avoidance (i.e. stewardship behavior) and data-archives of outcomes (injuries; near-misses; property damage). Together, these empirical findings might be conceptually interpreted as an initial indication of discriminant validity of the PRO-SAFE model, as related to "promotion-focused" approaches to safety management, which currently seems to be under-investigated.

c) Even if the paradigm of organizational proactivity has been broadly investigated across a broad range of work domains, phenomena and behaviors, to our knowledge there have been few studies of proactivity phenomena in the occupational health and safety domain (Parker et al., 2010; Turner et al., 2005). While the general research on proactivity stresses the importance of the interaction of differentiated motivational mechanism effects with proactive behavior outcomes (Fuller et al., 2012; Parker et al., 2010), the present contribution was primarily focused on the conceptual integration of different psychological mechanisms of proactivity which may support the expression of proactive behaviors related to safety in organizational settings, elaborating a holistic 
measurement model of safety-specific psychological tendencies of proactivity by individuals with a medium level of outcome generalizability. This allows us to give further evidence of discriminant and external validities of the paradigm of proactive motivation in the specific and complex domain of occupational safety, showing relatively unexplored conceptual links with other relevant theoretical paradigms from health psychology (Greenglass, 2002) and sociotechnical systems literature (Weick \& Sutclife, 2007).

\subsection{Research limitations and future studies}

Our research has strengths, like the use of multiple and eternal sources of information. However, several limitations need to be recognized.

Firstly, only a limited set of constructs was used in our nomological analysis. Therefore, it should be noted that future studies should be focused on the organizational antecedents (organizational and team related processes beyond safety leadership constructs) and individuals characteristics (personal dispositions; safety knowledge; risk perception), which may facilitate the development of a safety proactive motivations, interacting with other relevant psychological processes and contextual factors.

Secondly, we principally aimed to offer an integrative vision of the construct of proactive role orientation toward safety management. However, future research might investigate in what situations it may be more pertinent to focus attention on single components rather than proactive safety motivation as an overall construct. For instance, some components may be more relevant than the others in specific situations. Also, some research questions might be relevant to understand how different dimensions assessed by the PRO-SAFE tool may interact and/or act with other psychological and organizational variables in order to determine safety-specific emergent phenomena and proactive behaviors (Fuller et al., 2012). On the other hand, a general indicator may offer more advantages in terms of generalizability of its causal effects on a broader range of participative safety criteria variables. 
Thirdly, we tried to provide evidence of external validity of our construct measure of proactive role orientation toward safety management including supervisor rates of team proactivity and critical events at team level. However, as safety phenomena are discussed in the literature as the outcome of different processes at different organization levels of analysis (organizational departments; work teams), future research may use multilevel methodologies to explore in which extent the general construct of proactive role orientation toward safety management may be related to other collective safety phenomena in organizations, like safety climate (Zohar, 2008), and safety mindfulness (Weick \& Sutcliffe, 2007).

\subsection{Practical implications}

Our measurement tool of "proactive safety motivation" could constitute a survey diagnostic instrument to monitor the levels of participation and proactivity tendencies by workers and teams toward safety management and safety culture maturity in organizations, giving information about specific weak points and possible changes and improvements, with implications for safety interventions and human resource programs (Saracino, Curcuruto, Antonioni, Mariani, Guglielmi, \& Spadoni, 2015). A broader and composite understanding and perspective of safety motivation as presented may yield fruitful research in examining the issue of fostering and maintaining employee broad proactive orientation to safety management, considering multiple links between organizational features, motivational dimensions of proactivity and consequent effects and outcomes.

Conclusion The present article might provide an initial platform and stimulation for further discussion and empirical research on the organizational paradigm of proactivity in the domain of occupational safety, and how it can potentially relate to different facets of individual, group and organizational safety performances, and ultimately, the effective impact of workforce participation in dynamics of safety improvement. Although our validity evidence is still preliminary, findings 
suggest that a promotion-oriented approach focused on proactive motivations and behaviors by employees may offer precious insights for safety management. 


\section{References}

Avey, J. B., Avolio, B. J., Crossley, C. D., \& Luthans, F. (2009). Psychological ownership: Theoretical extensions, measurement and relation to work outcomes. Journal of Organizational Behavior, 30, 173-191. doi:10.1002/job.583

Bandura, A. (2001). Social cognitive theory: An agency perspective. Annual Review of Psychology, 52, 1-26. doi:10.1146/annurev.psych.52.1.1

Barling, J., Loughlin, C., \& Kelloway, E. K. (2002). Development and test of a model linking safety-specific transformational leadership and occupational safety. Journal of Applied Psychology, 87, 488-496. doi:10.1037/0021-9010.87.3.488

Christian, M. S., Bradley, J. C., Wallace, J. C., \& Burke, M. J. (2009). Workplace safety: a metaanalysis of the roles of person and situation factors. Journal of Applied Psychology, 94, 11031127. doi:10.1037/a0016172

Clarke, S. (2010). An integrative model of safety climate: Linking psychological climate and work attitudes to individual safety outcomes using meta-analysis. Journal of Occupational and Organizational Psychology, 83, 553-578. doi:10.1348/096317909X452122

Conchie, S. (2013). Transformational leadership, intrinsic motivation, and trust: A moderatedmediated model of workplace safety. Journal of Occupational Health Psychology, 18, 198210. doi.10.1037/a0031805

Crant, M. J. (2000). Proactive behavior in organizations. Journal of Management, 26, 435-462. doi:10.1177/014920630002600304

Curcuruto, M., Conchie, S., Mariani, M. G., \& Violante, F. S. (2015). The role of prosocial and proactive safety behaviors in predicting safety performance. Safety Science, 80, 317-323 doi:10.1016/j.ssci.2015.07.032 
Curcuruto, M., \& Griffin, M. A. (In press). Safety Proactivity in Organizations: The Initiative to Improve Individual, Team and Organizational Safety. In S. Parker \& U. Bindl (Eds). Proactivity at Work. New York, NY: Taylor \& Francis/Routledge.

Curcuruto, M., Guglielmi, D., \& Mariani, M. G. (2013). Organizational citizenship for safety: psycho-social processes of mediation. Psicologia Sociale, 8, 229-248. doi: 10.1482/74261

Curcuruto, M., Guglielmi, D., \& Mariani, M. G. (2014). A Diagnostic Tool to Evaluate the Proactivity Levels of Risk-Reporting Activities by the Workforce. Chemical Engineering Transactions, 36, 397-402. doi: 10.3303/CET1436067

Edwards, J. R. (2000). Multidimensional constructs in organizational behavior research: An integrative analytical framework. Organizational Research Methods, 4, 144-192. doi:10.1177/109442810142004

Fornell, C., \& Larcker, D. F. (1981). Evaluating structural equation models with unobservable variables and measurement error. Journal Of Marketing Research, 18, 39-50.

Frese, M., \& Fay, D. (2001). Personal Initiative: An Active Performance Concept for Work in The 21st Century. Research in Organizational Behavior, 23, 133-187.

Fuller, J. B., Marler, L. E., \& Hester, K. (2012). Bridge building within the province of proactivity. Journal of Organizational Behavior, 33, 1053-1070. doi:10.1002/job.1780

Gagné, M., \& Deci, E. L. (2005). Self-determination theory and work motivation. Journal of Organizational Behavior, 26, 331-362. doi:10.1002/job.322.

Geller, E. S. (2002). The participation factor. Boca Raton: CRC Press.

Grant, A. M., \& Ashford, S. J. (2008). The dynamics of proactivity at work. Research in Organizational Behavior, 28, 3-34.

Grant, A. M., \& Hofmann, D. A. (2011). Role expansion as a persuasion process : The interpersonal influence dynamics of role redefinition. Organizational Psychology Review, 1, 9-31. 
Greenglass, E. R. (2002). Proactive coping and quality of life management. In E. Frydenberg (Ed.), Beyond coping: Meeting goals, visions, and challenges (pp. 37-62). New York, NY: Oxford University Press.

Griffin, M. A., Cordery J., \& Soon, C. (2015). Dynamic safety capability: How organizations proactively change core safety systems. Organizational Psychology Review, 5, 1-21.

Griffin, M. A., \& Curcuruto, M. (2016). Safety Climate in Organizations. Annual Review of Organizational Psychology and Organizational Behavior, 3.

Griffin, M. A., Hodkiewicz, M. R., Dunster, J., Kanse, L., Parkes, K. R., Finnerty, D., Cordery, J. L., \& Unsworth, K. L. (2014). A conceptual framework and practical guide for assessing fitness-to-operate in the offshore oil and gas industry. Accident Analysis and Prevention, 68, 156-171. doi:10.1016/j.aap.2013.12.005

Griffin, M. A., Neal, A., \& Parker, S. K. (2007). A new model of work role performance: Positive behavior in uncertain and interdependent contexts. Academy of Management Journal, 50, 327-347. doi:10.5465/AMJ.2007.24634438

Guldenmund, F. W. (2010). (Mis)understanding safety culture and its relationship to safety management. Risk Analysis, 30, 1466-1480. doi:10.1111/j.1539-6924.2010.01452.x

Higgins, E. (2012). Beyond pleasure and pain: How motivation works. New York, NY US: Oxford University Press.

Hinkin, T. R. (1998). A Brief Tutorial on the Development of Measures for Use in Survey Questionnaires. Organizational Research Methods, 1, 104-121.

Hofmann, D. A., Morgeson, F. P., \& Gerras, S. J. (2003). Climate as a moderator of the relationship between leader-member exchange and content specific citizenship: Safety climate as an exemplar. Journal of Applied Psychology, 88, 170-178. doi:10.1037/0021-9010.88.1.170.

Hofmann, D. A., \& Tetrick, L. E. (Eds) (2003). Health and safety in organizations: A multi-level perspective. San Francisco: Jossey-Bass. 
Hollnagel, E. (2014). Safety-I and Safety-II. The Past and Future of Safety Management. Aldershot: Ashgate.

Hollnagel, E., Paries, J., Woods, D., \& Wreathall, J. (2012). Resilience Engineering in Practice. Aldershot: Ashgate.

Judge, T. A., \& Kammeyer-Mueller, J. D. (2012). General and specific measures in organizational behavior research: Considerations, examples, and recommendations for researchers. Journal Of Organizational Behavior, 33, 161-174. doi:10.1002/job.764

Kark, R., Katz-Navon, T., \& Delegach, M. (2015, February 9). The Dual Effects of Leading for Safety: The Mediating Role of Employee Regulatory Focus. Journal of Applied Psychology. Advance online publication. http://dx.doi.org/10.1037/a0038818

Katz-Navon, T., Naveh, E., \& Stern, Z. (2007). Safety self-efficacy and safety performance. Potential antecedents and the moderation effect of standardization. International Journal of Health Care Quality Assurance, 20, 572-584.

LeBreton, J. M., \& Senter, J. L. (2008). Answers to 20 Questions About Inter-rater Reliability and Inter-rater Agreement. Organizational Research Methods, 11, 815-852. doi:10.1177/1094428106296642

Mariani, M.G., Soldà, B., \& Curcuruto, M. (2015). Safety Behavior from A Self-determination Perspective. Medicina del Lavoro, 5, 333-341.

Mathieu, J.E., Gilson, L.L., \& Ruddy, T.M. (2006). Empowerment and team effectiveness: An empirical test of an integrated model. Journal of Applied Psychology, 91, 97-108. doi:10.1037/0021-9010.91.1.97

McAllister, D. J., Kamdar, D., Morrison, E., \& Turban, D. B. (2007). Disentangling role perceptions: How perceived role breadth, discretion, instrumentality, and efficacy relate to helping and taking charge. Journal Of Applied Psychology, 92, 1200-1211. doi:10.1037/00219010.92.5.1200 
Mearns, K., Rundmo, T., Flin, R., Gordon, R., \& Fleming, M. (2004). Evaluation of psychosocial and organizational factors in offshore safety: A comparative study. Journal Of Risk Research, 7, 545-561. doi:10.1080/1366987042000146193

Morrison, E., \& Phelps, C. C. (1999). Taking charge at work: Extra-role efforts to initiate workplace change. Academy Of Management Journal, 42, 403-419. doi:10.2307/257011

Neal, A., \& Griffin, M. A. (2006). A study of the lagged relationships among safety climate, safety motivation, safety behavior, and accidents at the individual and group levels. Journal of Applied Psychology, 91, 946-953. doi:10.1037/0021-9010.91.4.946

Ng, T.H.W, \& Feldman, D. C. (2012). Employee voice behavior: A meta-analytical test of the conservation of resources framework. Journal Of Organizational Behavior, 33, 216-234. doi:10.1002/job.754

Parker, S. K., Bindl, U. K., \& Strauss, K. (2010). Making things happen: A model of proactive motivation. Journal of Management, 36, 827-856. doi:10.1177/0149206310363732

Parker, S. K., \& Collins, C. G. (2010). Taking stock: Integrating and differentiating multiple proactive behaviors. Journal of Management, 36, 633-662. doi:10.1177/014920630832155

Parker, S. K., Williams, H. M., \& Turner, N. (2006). Modeling the antecedents of proactive behavior at work. Journal of Applied Psychology, 91, 636-652. doi:10.1037/00219010.91.3.636

Parker, S. K., \& Wu, C. H. (2013). Leading for proactivity: How leaders cultivate staff who make things happen. In D. V. Day (Ed), The Oxford Handbook of Leadership and Organizations. Oxford: Oxford University Press.

Peiró, J. M. (2008). Stress and coping at work: New research trends and their implications for practice. In K. Näswall, J. Hellgren \& M. Sverke (Eds.), The individual in the changing working life (pp. 284-310). New York, NY US: Cambridge University Press. 
Pierce, J. L., Jussila, I., \& Cummings, A. (2009). Psychological ownership within the job design context: revision of the job characteristics model. Journal of Organizational Behavior, 30, 477-496. doi:10.1002/job.550

Reason, J. (2008). The human contribution: unsafe acts, accidents and heroic recoveries. Manchester: Ashgate.

Saracino, A., Curcuruto, M., Antonioni, G., Mariani, M. G., Guglielmi, D., \& Spadoni, G. (2015). Proactivity-and-consequence-based safety incentive (PCBSI) developed with a fuzzy approach to reduce occupational accidents. Safety Science, 79, 175-183. doi:10.1016/j.ssci.2015.06.011

Scott, N., Fleming, M., \& Kellowey, E. K. (2014). Understanding Why Employees Behave Safely from a Self-Determination Theory Perspective. In Gagné, M. (Ed), Oxford handbook of work engagement, motivation, and self-determination theory (pp. 276-294), New York, Oxford University Press.

Simard, M., \& Marchand, A. (1995). A multilevel analysis of organizational factors related to the taking of safety initiatives by work groups. Safety Science, 21, 113-129.

Speier, C., \& Frese, M. (1997). Generalized self-efficacy as a mediator and moderator between control and complexity at work and personal initiative: A longitudinal study in East Germany. Human Performance, 10, 171-192. doi:10.1207/s15327043hup1002_7

Spreitzer, G. M. (1996). Social structural characteristics of psychological empowerment. Academy Of Management Journal, 39, 483-504. doi:10.2307/256789

Stanton, J. M., Sinar, E. F., Balzer, W. K., \& Smith, P. C. (2002). Issues and strategies for reducing the length of self-report scales. Personnel Psychology, 55, 167-194. doi:10.1111/j.17446570.2002.tb00108.x 
Strauss, K., Griffin, M. A., \& Parker, S. K. (2012). Future work selves: How salient hoped-for identities motivate proactive career behaviors. Journal of Applied Psychology, 97, 580-98. doi: $10.1037 / \mathrm{a} 0026423$

Tucker, S., \& Turner, N. (2015). Sometimes it hurts when supervisors don't listen: Antecedents and consequences of safety voice among young workers. Journal of Occupational Health Psychology, 20, 72-81. doi: 10.1037/a0037756

Turner, N., Chmiel, N., \& Walls, M. (2005). Railing for Safety: Job Demands, Job Control, and Safety Citizenship Role Definition. Journal of Occupational Health Psychology, 10, 504512. doi:10.1037/1076-8998.10.4.504

Wallace, C., \& Chen, G. (2006). A multilevel integration of personality, climate, self-regulation, and performance. Personnel Psychology, 59, 529-557. doi:10.1111/j.1744-6570.2006.x

Weick, K. E., \& Sutcliffe, K. M. (2007). Managing the Unexpected. Resilient performance in the age of uncertainty. San Francisco, CA US: Jossey-Bass.

Zohar, D. (2008). Safety Climate and Beyond: A Multi-level Multi-climate Framework, Safety Science, 46, 376-387. 
Table 1. Psychological drivers of a "proactive safety-role orientation": construct descriptions, typologies and key references

\begin{tabular}{|c|c|c|c|}
\hline Dimension & Construct description & Construct typology & Key references \\
\hline $\begin{array}{l}\text { Role breadth } \\
\text { self-efficacy }\end{array}$ & $\begin{array}{l}\text { Perceived confidence in own abilities to carry out a broader and more } \\
\text { participative role in organizational safety processes, going beyond the } \\
\text { formalized role-tasks and the prescribed technical requirements }\end{array}$ & $\begin{array}{l}\text { "Can do" motivation } \\
\text { (Outcome-expectancy) }\end{array}$ & $\begin{array}{l}\text { Bandura, 2001; } \\
\text { Katz-Navon et al., 2007; } \\
\text { Parker et al., } 2010\end{array}$ \\
\hline $\begin{array}{l}\text { Perceived } \\
\text { control }\end{array}$ & $\begin{array}{l}\text { Perception of subjective impact and relevance of own contributions to } \\
\text { safety maintenance processes, improvement initiative, problem-solving } \\
\text { activities in own organizational units and/or teams }\end{array}$ & $\begin{array}{l}\text { “Can do" motivation } \\
\text { (Outcome-expectancy) }\end{array}$ & $\begin{array}{l}\text { Frese \& Fay, 2001; } \\
\text { Parker et al., 2010; } \\
\text { Spreitzer, } 1996\end{array}$ \\
\hline $\begin{array}{l}\text { Psychological } \\
\text { ownership }\end{array}$ & $\begin{array}{l}\text { Extent which workers feel safety programs, processes and initiatives in } \\
\text { organizations as something of personal concern and psychologically } \\
\text { "owned" }\end{array}$ & $\begin{array}{l}\text { “Reason to" motivation } \\
\text { (Subjective-valence) }\end{array}$ & $\begin{array}{l}\text { Gagnè \& Deci, 2005; } \\
\text { Parker et al., 2010; } \\
\text { Pierce et al.. } 2009\end{array}$ \\
\hline $\begin{array}{l}\text { Felt } \\
\text { responsibility }\end{array}$ & $\begin{array}{l}\text { Individual feeling to be personally in charge to set and strive to assure safe } \\
\text { work conditions in every circumstance, even if this falls beyond the formal } \\
\text { role accountabilities, or technical tasks and requirements of a job position }\end{array}$ & $\begin{array}{l}\text { “Reason to" motivation } \\
\text { (Subjective-valence) }\end{array}$ & $\begin{array}{l}\text { Geller, 2002; } \\
\text { Morrison \& Phelps, 1999; } \\
\text { Parker et al., } 2010\end{array}$ \\
\hline $\begin{array}{l}\text { Anticipation } \\
\text { orientation }\end{array}$ & $\begin{array}{l}\text { Future-oriented mindset to predict and prevent threats, risks and uncertain } \\
\text { critical events for safety before that they produce effective negative } \\
\text { consequences for safetv }\end{array}$ & $\begin{array}{l}\text { Future-orientation } \\
\text { (Protective focus) }\end{array}$ & $\begin{array}{l}\text { Greenglass, 2002; } \\
\text { Hollnagel et al., 2012; } \\
\text { Weick \& Sutcliffe, } 2007\end{array}$ \\
\hline $\begin{array}{l}\text { Improvement } \\
\text { orientation }\end{array}$ & $\begin{array}{l}\text { Future-oriented mindset to continuously exceed safety standards } \\
\text { performance, showing acceptance of procedural changes, and availability to } \\
\text { learn new procedures and competences }\end{array}$ & $\begin{array}{l}\text { Future-orientation } \\
\text { (Promotive focus) }\end{array}$ & $\begin{array}{l}\text { Frese \& Fay, 2001; } \\
\text { Griffin et al., 2016; } \\
\text { Hollnagel et al., } 2012\end{array}$ \\
\hline
\end{tabular}


Table 2. Psychological drivers of a "proactive safety-role orientation": descriptive and correlation statistics in the overall sample $(\mathrm{N}=523)$ and in its subsamples

\begin{tabular}{lllllllll}
\hline Factors & $\mathbf{M}$ & SD & $\mathbf{1}$ & $\mathbf{2}$ & $\mathbf{3}$ & $\mathbf{4}$ & $\mathbf{5}$ & $\mathbf{6}$ \\
\hline Overall sample (N=761) & & & & & & & & \\
1. Role breadth self-efficacy & 3.68 & .82 & $(.85)$ & & & & & \\
2. Control perception & 3.65 & .78 & $.48^{* *}$ & $(.78)$ & & & & \\
3. Psychological ownership & 3.98 & .79 & $.30^{* *}$ & $.24^{* *}$ & $(.85)$ & & & \\
4. Felt responsibility & 4.01 & .73 & $.41^{* *}$ & $.34^{* *}$ & $.47^{* *}$ & $(.81)$ & & \\
5. Improvement orientation & 4.18 & .77 & $.24^{* *}$ & $.26^{* *}$ & $.27^{* *}$ & $.32^{* *}$ & $(.79)$ & \\
6. Anticipation orientation & 3.68 & .88 & $.46^{* *}$ & $.39^{* *}$ & $.36^{* *}$ & $.51^{* *}$ & $.33^{* *}$ & $(.89)$ \\
\hline Chemical sample (N=327) & & & & & & & & \\
1. Role breadth self-efficacy & 3.71 & .83 & $(.85)$ & & & & & \\
2. Control perception & 3.84 & .74 & $.49^{* *}$ & $(.79)$ & & & & \\
3. Psychological ownership & 4.14 & .83 & $.31^{* *}$ & $.25^{* *}$ & $(.87)$ & & & \\
4. Felt responsibility & 4.03 & .78 & $.45^{* *}$ & $.47^{* *}$ & $.48^{* *}$ & $(.84)$ & & \\
5. Improvement orientation & 4.17 & .81 & $.30^{* *}$ & $.31^{* *}$ & $.29^{* *}$ & $.34^{* *}$ & $(.77)$ & \\
6. Anticipation orientation & 3.77 & .88 & $.44^{* *}$ & $.39^{* *}$ & $.31^{* *}$ & $.55^{* *}$ & $.36^{* *}$ & $(.88)$ \\
\hline Manufacturing sample (N=196) & & & & & & & & \\
1. Role breadth self-efficacy & 3.81 & .73 & $(.80)$ & & & & & \\
2. Control perception & 3.77 & .70 & $.42^{* *}$ & $(.76)$ & & & & \\
3. Psychological ownership & 3.95 & .62 & $.28^{* *}$ & $.30^{* *}$ & $(.79)$ & & & \\
4. Felt responsibility & 4.05 & .69 & $.39^{* *}$ & $.22^{* *}$ & $.43^{* *}$ & $(.81)$ & & \\
5. Improvement orientation & 4.07 & .80 & $.21^{* *}$ & $.19^{* *}$ & $.27^{* *}$ & $.32^{* *}$ & $(.79)$ & \\
6. Anticipation orientation & 3.71 & .82 & $.47^{* *}$ & $.41^{* *}$ & $.35^{* *}$ & $.45^{* *}$ & $.33^{* *}$ & $(.85)$ \\
\hline
\end{tabular}

Note: Coefficients of Alpha are presented in parentheses along diagonal;

${ }^{*} \mathrm{p}<.05 ;{ }^{* *} \mathrm{p}<.01$ 
Table 3. Comparison of a priori factor structure models (CFA) of PRO-SAFE questionnaire: overall sample $(\mathrm{N}=523)$

\begin{tabular}{|c|c|c|c|c|c|c|c|c|}
\hline Models & $\begin{array}{c}\text { Psychological } \\
\text { Factors }\end{array}$ & $\begin{array}{l}\text { 2nd order } \\
\text { factors }\end{array}$ & $\begin{array}{c}\text { Model } \\
\text { Description }\end{array}$ & $x^{2}$ & Df & CFI & RMSEA & $\mathrm{BIC}$ \\
\hline $\begin{array}{l}\text { Hypothesized } \\
\text { model }\end{array}$ & $\begin{array}{c}\text { Six first order factors } \\
(A O, C P, I O, F R, P O, S E)\end{array}$ & One & $\begin{array}{l}\text { A multiple set of safety-specific } \\
\text { psychological states of proactivity with } \\
\text { a superordinate general dimension of } \\
\text { proactive safety-role orientation }\end{array}$ & 411.6 & 246 & .95 & .04 & 746.8 \\
\hline $\begin{array}{l}\text { First order } \\
\text { model }\end{array}$ & Only method & None & All items loading to only a single factor & 2143.1 & 252 & .51 & .12 & 2411.1 \\
\hline $\begin{array}{l}\text { Alternative } \\
\text { model } 1\end{array}$ & $\begin{array}{l}\text { Three first order factors: } \\
(S E-C P) ;(F R-P O) ;(A O-I O)\end{array}$ & None & $\begin{array}{l}\text { The items loading in three distinct } \\
\text { psychological factors drivers: can do } \\
\text { motivation, reason to motivation, future } \\
\text { orientation }\end{array}$ & 1372.9 & 252 & .71 & .10 & 1671 \\
\hline $\begin{array}{l}\text { Alternative } \\
\text { model } 2\end{array}$ & $\begin{array}{c}\text { Six first order factors } \\
(A O, C P, I O, F R, P O, S E)\end{array}$ & None & $\begin{array}{l}\text { A multiple set of safety-specific } \\
\text { psychological states of proactivity } \\
\text { without second order factors }\end{array}$ & 383.4 & 237 & .95 & .04 & 764.2 \\
\hline $\begin{array}{l}\text { Alternative } \\
\text { model } 3\end{array}$ & $\begin{array}{l}\text { Six first order factors } \\
(A O, C P, I O, F R, P O, S E)\end{array}$ & Two & $\begin{array}{l}\text { A multiple set of safety-specific } \\
\text { psychological states of proactivity with } \\
\text { two second order factors: proactive } \\
\text { motivation and future orientation }\end{array}$ & 430.5 & 245 & .95 & .04 & 757.7 \\
\hline
\end{tabular}

Legend: $\mathrm{AO}=$ anticipation orientation; $\mathrm{CP}=$ control perception; $\mathrm{FR}=$ felt responsibility; $\mathrm{IO}=$ improvement orientation; $\mathrm{PO}=$ psychological ownership; $\mathrm{SE}=$ role breadth self-efficacy 
Table 4. Comparison of a priori factor structure models (CFA) of PRO-SAFE questionnaire: chemical sample (N=327)

\begin{tabular}{|c|c|c|c|c|c|c|c|c|}
\hline Models & $\begin{array}{l}\text { Psychological } \\
\text { factors }\end{array}$ & $\begin{array}{l}\text { 2nd order } \\
\text { factors }\end{array}$ & $\begin{array}{c}\text { Model } \\
\text { Description }\end{array}$ & $x^{2}$ & Df & CFI & RMSEA & BIC \\
\hline $\begin{array}{l}\text { Hypothesized } \\
\text { model }\end{array}$ & $\begin{array}{c}\text { Six first order factors } \\
(A O, C P, I O, F R, P O, S E)\end{array}$ & One & $\begin{array}{l}\text { A multiple set of safety-specific } \\
\text { psychological states of proactivity with } \\
\text { a superordinate general dimension of } \\
\text { proactive safety-role orientation }\end{array}$ & 459.1 & 246 & .94 & .05 & 771.8 \\
\hline $\begin{array}{l}\text { First order } \\
\text { model }\end{array}$ & Only method & None & All items loading to only a single factor & 1962 & 252 & .52 & .14 & 2240.1 \\
\hline $\begin{array}{l}\text { Alternative } \\
\text { model } 1\end{array}$ & $\begin{array}{l}\text { Three first order factors: } \\
(S E-C P) ;(F R-P O) ;(A O-I O)\end{array}$ & None & $\begin{array}{l}\text { The items loading in three distinct } \\
\text { psychological factors drivers: can do } \\
\text { motivation, reason to motivation, future } \\
\text { orientation }\end{array}$ & 1631.92 & 252 & .62 & .13 & 1909.4 \\
\hline $\begin{array}{l}\text { Alternative } \\
\text { model } 2\end{array}$ & $\begin{array}{c}\text { Six first order factors } \\
(A O, C P, I O, F R, P O, S E)\end{array}$ & None & $\begin{array}{l}\text { A multiple set of safety-specific } \\
\text { psychological states of proactivity } \\
\text { without second order factors }\end{array}$ & 439.2 & 237 & .94 & .05 & 804 \\
\hline $\begin{array}{l}\text { Alternative } \\
\text { model } 3\end{array}$ & $\begin{array}{c}\text { Six first order factors } \\
(A O, C P, I O, F R, P O, S E)\end{array}$ & Two & $\begin{array}{l}\text { A multiple set of safety-specific } \\
\text { psychological states of proactivity with } \\
\text { two second order factors: proactive } \\
\text { motivation and future orientation }\end{array}$ & 476.6 & 245 & .94 & .05 & 784.7 \\
\hline
\end{tabular}

Legend: $\mathrm{AO}=$ anticipation orientation; $\mathrm{CP}=$ control perception; $\mathrm{FR}=$ felt responsibility; $\mathrm{IO}=$ improvement orientation; $\mathrm{PO}=$ psychological ownership; $\mathrm{SE}=$ role breadth self-efficacy 
Table 5. Comparison of a priori factor structure models (CFA) of PRO-SAFE questionnaire: manufacturing sample (N=196)

\begin{tabular}{|c|c|c|c|c|c|c|c|c|}
\hline Models & $\begin{array}{l}\text { Psychological } \\
\text { factors }\end{array}$ & $\begin{array}{l}\text { 2nd order } \\
\text { factors }\end{array}$ & $\begin{array}{c}\text { Model } \\
\text { Description }\end{array}$ & $x^{2}$ & Df & CFI & RMSEA & $\mathrm{BIC}$ \\
\hline $\begin{array}{l}\text { Hypothesized } \\
\text { model }\end{array}$ & $\begin{array}{c}\text { Six first order factors } \\
(A O, C P, I O, F R, P O, S E)\end{array}$ & One & $\begin{array}{l}\text { A multiple set of safety-specific } \\
\text { psychological states of proactivity with } \\
\text { a superordinate general dimension of } \\
\text { proactive safety-role orientation }\end{array}$ & 421.3 & 246 & .94 & .06 & 714 \\
\hline $\begin{array}{l}\text { First order } \\
\text { model }\end{array}$ & Only method & None & All items loading to only a single factor & 1429.2 & 252 & .57 & .15 & 1689.3 \\
\hline $\begin{array}{l}\text { Alternative } \\
\text { model } 1\end{array}$ & $\begin{array}{l}\text { Three first order factors: } \\
(S E-C P) ;(F R-P O) ;(A O-I O)\end{array}$ & None & $\begin{array}{l}\text { The items loading in three distinct } \\
\text { psychological factors drivers: can do } \\
\text { motivation, reason to motivation, future } \\
\text { orientation }\end{array}$ & 1367.2 & 252 & .61 & .13 & 1627.4 \\
\hline $\begin{array}{l}\text { Alternative } \\
\text { model } 2\end{array}$ & $\begin{array}{l}\text { Six first order factors } \\
(A O, C P, I O, F R, P O, S E)\end{array}$ & None & $\begin{array}{l}\text { A multiple set of safety-specific } \\
\text { psychological states of proactivity } \\
\text { without second order factors }\end{array}$ & 398.8 & 237 & 94 & .06 & 730.3 \\
\hline $\begin{array}{l}\text { Alternative } \\
\text { model } 3\end{array}$ & $\begin{array}{c}\text { Six first order factors } \\
(A O, C P, I O, F R, P O, S E)\end{array}$ & Two & $\begin{array}{l}\text { A multiple set of safety-specific } \\
\text { psychological states of proactivity with } \\
\text { two second order factors: proactive } \\
\text { motivation and future orientation }\end{array}$ & 434.7 & 245 & .91 & .06 & 723.9 \\
\hline
\end{tabular}

Legend: $\mathrm{AO}=$ anticipation orientation; $\mathrm{CP}=$ control perception; $\mathrm{FR}=$ felt responsibility; $\mathrm{IO}=$ improvement orientation; $\mathrm{PO}=$ psychological ownership; $\mathrm{SE}=$ role breadth self-efficacy 
Table 6. Summary of the loading coefficient indices (CFA) in the two organizational samples (N=523).

\begin{tabular}{|c|c|c|}
\hline Item content & $\begin{array}{c}\text { Sample } 1 \\
(\mathrm{~N}=327)\end{array}$ & $\begin{array}{c}\text { Sample } 2 \\
(\mathrm{~N}=196)\end{array}$ \\
\hline \multicolumn{3}{|l|}{ Role Breadth Self-Efficacy } \\
\hline SE4 Feeling confident in... analyzing recurring problems for safety to propose solutions & .85 & .88 \\
\hline SE3 Feeling confident in... devising new methods to improve safety in my work area & .79 & .86 \\
\hline SE2 Feeling confident in... helping to set the safety goals in one's own work-team & .74 & .81 \\
\hline $\begin{array}{l}\text { SE1 Feeling confident in... dealing with colleagues from departments to discuss improvements } \\
\text { Control perception }\end{array}$ & .70 & .67 \\
\hline CP2 Perceiving to being able to make significant contributions to the safety of the work area & .85 & .80 \\
\hline CP4 Perceiving to have a lot of opportunities to influence the situation if something of relevant for safety happens & .68 & .70 \\
\hline CP3 Perceiving that one's own actions have great importance for the safety of the work-team & .67 & 60 \\
\hline $\begin{array}{l}\text { CP1 Perceiving that most of the safety problems in the work are under one's own control } \\
\text { Psychological Ownership }\end{array}$ & .59 & .54 \\
\hline PO2 Being personally concerned for... worker involvement in programs for safety improvement & .85 & .87 \\
\hline PO1 Being personally concerned for... stimulating worker initiatives for safety & .83 & .85 \\
\hline PO4 Being personally concerned for... personal engagement for safety by every team member & .75 & .79 \\
\hline $\begin{array}{l}\text { PO3 Being personally concerned for... considering new ways to manage safety in the work activities } \\
\text { Felt Responsibility }\end{array}$ & .71 & .77 \\
\hline FR4 To strive hard to be an example for one's own commitment to safety & .77 & .80 \\
\hline FR3 To pay attention to the errors that colleagues can take in their work & .75 & .78 \\
\hline FR1 Feeling a sense of personal responsibility in trying to make changes for safety & 69 & .75 \\
\hline $\begin{array}{l}\text { FR2 Depend on me to make improvements to the safety of the workplace } \\
\text { Anticipation Orientation }\end{array}$ & .68 & .59 \\
\hline AO4 Anticipating a risk or a safety problem thinking of the possible alternative scenarios & .85 & .89 \\
\hline AO3 Looking the situations from various safety perspectives to find the appropriate solutions & .82 & .85 \\
\hline AO1 Even before they really happen, thinking about various risky situations for safety & .81 & .82 \\
\hline $\begin{array}{l}\text { AO2 Looking forward to ensure that future safety in my team is good and well-defined } \\
\text { Improvement Orientation }\end{array}$ & .73 & .80 \\
\hline IO3 Learning continuously new things on safety might make you less efficient in carrying on your work & .81 & .87 \\
\hline IO4 The time dedicated to safety related improvement issues might implicate less time to achieve the production & 69 & .84 \\
\hline IO2 Sometimes the safety procedures and regulations are changed just for the sake of doing it & .61 & .83 \\
\hline IO1 When the work goes on smoothly there is no need to think about changing things to improve safety & 60 & .80 \\
\hline
\end{tabular}


Table 7. Correlation statistics of PRO-SAFE dimensions' measures: nomological network (N=523)

\begin{tabular}{|c|c|c|c|c|c|c|c|c|c|c|c|c|}
\hline Factor & 1 & 2 & 3 & 4 & 5 & 6 & 7 & 8 & 9 & 10 & 11 & 12 \\
\hline $\begin{array}{l}\text { 1.Proactive safety role orientation } \\
\text { (general dimension) }\end{array}$ & $(.93)$ & & & & & & & & & & & \\
\hline 2. Psychological ownership & $.69^{* *}$ & $(.87)$ & & & & & & & & & & \\
\hline 3. Role breadth self-efficacy & $.77^{* *}$ & $.35^{* *}$ & $(.89)$ & & & & & & & & & \\
\hline 4. Improvement orientation & $.61^{* *}$ & $.32 * *$ & $.27^{* *}$ & $(.80)$ & & & & & & & & \\
\hline 5. Anticipation orientation & $.79^{* *}$ & $.36^{* *}$ & $.42^{* *}$ & $.30 * *$ & $(.88)$ & & & & & & & \\
\hline 6. Control perception & $.67^{* *}$ & $.24^{* *}$ & $.31^{* *}$ & $.33^{* *}$ & $.30 * *$ & $(.78)$ & & & & & & \\
\hline 7. Felt responsibility & $.81^{* *}$ & $.38^{* *}$ & $.41^{* *}$ & $.28^{* *}$ & $.51^{* *}$ & $.24^{* *}$ & $(.86)$ & & & & & \\
\hline 8. Safety transf. leadership & $.42^{* *}$ & $.18^{*}$ & $.25^{* *}$ & $.16^{* *}$ & $.28^{* *}$ & $.33^{* *}$ & $.35^{* *}$ & & & & & \\
\hline 9. Safety initiative & $.58^{\star *}$ & $.36^{* *}$ & $.45^{\star *}$ & $.24^{\star *}$ & $.54^{* *}$ & $.26^{* *}$ & $.55^{\star *}$ & $.25^{* *}$ & $(.75)$ & & & \\
\hline 10. Safety voice & $.54^{\star *}$ & $.40^{* *}$ & $.41^{* *}$ & $.29^{* *}$ & $.51^{* *}$ & $.22^{* *}$ & $.57^{* *}$ & $.23^{* *}$ & $.69^{* *}$ & $(.78)$ & & \\
\hline 11. Safety stewardship & $.19^{* *}$ & .02 & $.22^{* *}$ & $.18^{*}$ & $.38^{* *}$ & .05 & $.32^{* *}$ & $.26^{* *}$ & $.58^{* *}$ & $.65^{* *}$ & $(.93)$ & \\
\hline 12. Risk-taking behaviour & $-.25^{\star *}$ & $-.20^{* *}$ & -.08 & $-.23^{* *}$ & $-.19 * *$ & $-.17^{*}$ & -.12 & $-.15^{*}$ & .07 & -.12 & $-.18^{*}$ & $(.83)$ \\
\hline
\end{tabular}

Note: Coefficients of Alpha are presented in parentheses along diagonal;

${ }^{*} \mathrm{p}<.05 ;{ }^{* *} \mathrm{p}<.01$ 


\section{Appendix 1}

Item development. A research group composed of faculty members and associates by two European universities generated 133 items representing the six theory-driven components of a "proactive safety orientation" assessment tool. All the members of the research team were previously involved in research in the field of occupational health and safety. In the most part of cases the items were generated from existing scales from the organizational behavior literature on proactivity phenomena, which were adapted to safety content issues.

Content item interviews. This pool of items was submitted to a group of twelve expert practitioners (i.e. safety managers, team safety heads, safety professional consultants) in order to examine the content and the face validity of new items developed and their ease of comprehension. This interview phase also enabled the research team to identify ambiguities, redundancies and repetitions among the items for each single dimension. Fifteen items were eliminated at the end of this phase after consultation with the group of safety experts about content-validity, clarity and non-redundancy.

Item reduction. We followed the guidelines of Stanton et al. (2002) for item reduction, which recommends examining external relationships with theoretically linked constructs in an effort to retain items that assess the full construct. Selecting items based on reliability with each item removed, and the corrected item-total correlations, maintained the scale's internal consistency (Cronbach's alpha). Then, the subscale items were reviewed to determine the extent to which each was redundant with others. Items that were less duplicative, theoretically stronger predictors of the outcome variables and maintained adequate internal reliability were proposed to: (1) capture the breadth of the construct, (2) enhance internal reliability.

The resulting final pool of 66 items was pretested with a small sample of technical workers to test the reliability psychometric property of every single scale of the research model. The participants were contacted with the help of a private HR training and development institution. The questionnaires were administered in five different organizational 
settings with different typologies and magnitude of risks for health and safety (i.e.

engineering; chemistry; sanitary; food; pharmacy). A questionnaire was administrated with a short letter of invitation explaining the research aims of the survey. All scales were presented as a five-point Likert response set. At the end, 102 electronic questionnaires were returned (the response rate was around $80 \%$ ). $58.3 \%$ of the final respondents were women. The average age of the workers was 36 years. Job tenure was between 5 and 10 years for $64.3 \%$ of the sample. $54.4 \%$ of the participants had a degree.

Final selection. Using each of the criteria described above, the 65 items were reduced to 30 (5 items for each of the 6 components). Internal reliability for the six components were: role-breadth self-efficacy ( $\alpha=.95)$; control perception $(\alpha=.87)$; psychological ownership $(\alpha=.91)$; felt responsibility ( $\alpha=.81)$; improvement orientation $(\alpha=.84)$; anticipatory orientation $(\alpha=.89)$. In all six cases, the average of the corrected item-total correlation indices was around .67 or higher. 